\title{
The impact of the COVID-19 pandemic on people with neurological disorders: an urgent need to enhance the health care system's preparedness
}

\author{
Silvia Zullo ${ }^{1}$ - Francesca Ingravallo ${ }^{2}$. Vittorio Crespi ${ }^{3} \cdot$ Marta Cascioli $^{4} \cdot$ Roberto D'Alessandro $^{5} \cdot$ Marcella Gasperini $^{6}$. \\ Chiara Lalli $^{7}$. Alessandra Lugaresi ${ }^{8,9}$. Maura Marogna ${ }^{10}$. Maurizio Mori ${ }^{11}$ - Ilaria Pesci ${ }^{12}$. Francesca Pistoia $^{13}$.

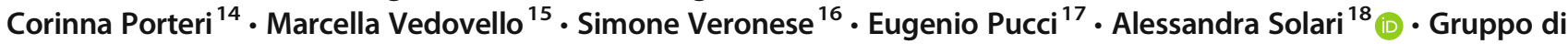 \\ Studio "Bioetica e Cure Palliative" of the Italian Neurological Society
}

Published online: 12 January 2021

(C) Fondazione Società Italiana di Neurologia 2021

\section{Background}

Italy was the first nation in Europe to be affected by COVID19 pandemic, and it was subjected to a level 1 national lockdown for almost 2 months (from March 9 to May 4, 2020) [1]. During the mandatory lockdown, 29,684 deaths due to COVID-19 were registered, 23,163 of which (78\%) were in four Northern regions: Lombardy, Emilia Romagna, Piedmont, and Veneto [2]. This health emergency highlighted the imbalance existing between the needs of individuals (prevention, diagnosis, treatment) and available resources (services, supplies, professionals, and research). In particular, the reorganization of health services and the social distancing measures implemented to contain the spread of the SARSCoV-2, together with people's fears of being infected and

Alessandra Solari

Alessandra.Solari@istituto-besta.it

Department of Legal Studies, University of Bologna, Bologna, Italy

2 Department of Medical and Surgical Sciences, University of Bologna, Bologna, Italy

3 Ethics Committee "Brianza", S. Gerardo Hospital, Monza, Italy

4 Hospice 'La Torre sul Colle', Azienda USL Umbria 2, Spoleto, Italy

5 Servizio di Epidemiologia e Biostatistica, Istituto delle Scienze Neurologiche di Bologna, Bologna, Italy

6 Rehabilitation Department, Marzana Hospital, AULSS 9 (VR), Marzana, Italy

7 Università “La Sapienza”, Rome, Italy

8 UOSI Riabilitazione Sclerosi Multipla, IRCCS Istituto delle Scienze Neurologiche di Bologna, Bologna, Italy the lack of targeted information campaigns, have led to a series of consequences for both patients and their families. As far as the neurological field is concerned, the impact of this "healthcare void" has been particularly remarkable for people suffering from chronic neurological conditions, as well as for those with neurological emergencies, and has resulted in worse health outcomes. In some instances, the criteria adopted for the allocation of health resources during the COVID-19 pandemic have penalized patients with neurological diseases [3].

Within the context of a service transformed by the pandemic health emergency, there is a need to adapt triage protocols to consider distributive justice when the "ordinary" criteria can no longer guarantee the best possible allocation. Such "extraordinary" triage protocols, specific to each neurological

di Scienze Biomediche e Neuromotorie, Università di Bologna, Bologna, Italy

1 SC Neurologia, Ospedale Villa Scassi ASL3, Genoa, Italy

11 Dipartimento di filosofia e scienze dell'educazione, University of Turin, Turin, Italy

12 Multiple Sclerosis Center, Ospedale di Vaio, Fidenza, PR, Italy

13 Department of Biotechnology and Applied Clinical Sciences, University of L'Aquila, L'Aquila, Italy

14 Bioethics Unit, IRCCS Istituto Centro San Giovanni di Dio Fatebenefratelli, Brescia, Italy

15 Neurology Unit, ASST Papa Giovanni XXIII, Bergamo, Italy

16 Fondazione FARO, Turin, Italy

17 UOC Neurologia, ASUR Marche, Fermo, Italy

18 Unit of Neuroepidemiology, Fondazione IRCCS Istituto Neurologico Carlo Besta, Via Celoria 11, 20133 Milan, Italy 
disease, together with disease-specific mortality indicators, should be adopted instead of the prognostic scales currently in use. The latter have limitations in themselves and were not designed to be used in the context of health care resource shortage [4].

\section{The health care needs of the neurological patient: from the "ordinary" to the "extraordinary"}

The substantial reorganization of health services due to the COVID-19 emergency has involved neurological services. Data from Spain, in particular the Madrid area, show that 95\% of hospitals have re-allocated neurologists to assist patients with COVID-19, and the number of beds in neurology wards was reduced by $89 \%$ [5]. The pandemic has uncovered the inadequate health care of people with neurological diseases, particularly in those areas already suffering from a lack of hospital-community integration. The shift in health resources for the care of patients with COVID-19 together with the social distancing measures has threatened neuro-rehabilitation, not only in the ordinary outpatient setting but also for inpatient and home care services [3,6]. As an example, the COVID-19 pandemic was associated with deleterious wideranging effects on people with Parkinson's disease, above all those living alone, with low income or belonging to ethnic minorities [7], and this was worsened by the greater difficulty in accessing drug treatments [8], leading to inadequate symptom control and increased disability. Professionals also reported a dramatic impact of COVID-19 on healthcare functioning, which manifested from the earliest stages of the pandemic. Over $90 \%$ of 200 neuro-pediatric services from 49 countries reported changes in outpatient care, with reduced access to EEG examination, and closure or limitation of the activity of the centers, including surgical procedures [9].

The care of patients with chronic neurological disorders has been typically based on "by pathology" outpatient clinics. However, the management of the needs of these patients and their caregivers was already substandard, particularly in those in the advanced stage of progressive disorders (such as amyotrophic lateral sclerosis, dementias, brain tumors, multiple sclerosis, and Parkinson's disease) mainly due to lack of service organization and integration, including community care and, when indicated, palliative care [10]. The sudden restriction in access to these clinics and the hospital reorganization which occurred in March-April 2020 have revealed a lack of health care pathways which could be rapidly implemented to secure continuity of care for this vulnerable patient population [11]. This has been the case in Italy, Spain, and other European countries hit by the COVID-19 pandemic [12].

Another important consequence concerns end-of-life and palliative care. The health emergency has reduced the response to the medical as well as the social needs of people suffering from chronic and disabling neurological disorders. Together with a sudden change in the health care organization, this frail patient population has experienced an unprecedented sense of loneliness and abandonment. The scarcity of (neuro) palliative services has especially impacted patients with severe neurological disorders and complex health care needs. The closure of nursing homes to visitors has removed the family network, the volunteers, and all the health care professionals in the so-called deferrable services, which are in fact essential to meeting the wide bio-psycho-social needs of this patient population. Furthermore, the lack of advance care planning (ACP) has challenged the decision-making of physicians and relatives/significant others of patients who are unable to communicate their wishes or have lost cognitive ability, in choosing health care options that are aligned with the patient's preferences and values.

\section{Public communication and information}

Despite the initial concerns related to the clustering of stroke unit activities in a few centers [3], the management of acute neurovascular emergencies has been fairly maintained in the majority of countries during the COVID-19 outbreak [13-15]. However, there has been a substantial decline in hospital admissions of stroke patients, which has been reported since the beginning of the pandemic [16], despite the increased risk of acute cerebrovascular disease in patients with COVID-19 [17]. This decrease has been accompanied by an increased time between the onset of symptoms and access to the emergency unit [18] and a higher prevalence of severe strokes upon admission [13]. It is likely that patients with mild or transient symptoms did not go to hospital for fear of being infected [13, 19]. It is also possible that social distancing and isolation may have played a role in the failure to recognize symptoms. However, considering that the decrease in some cases reached $80 \%$, it is assumed that even patients with more serious symptoms were not admitted to stroke units [16]. This would also seem to be the case for stroke patients with particularly severe neurological damage or concomitant respiratory failure $[3,19,20]$. In Italy and France, it is possible that older patients with significant co-morbidities, living in nursing homes or in long-term 
facilities, were not hospitalized due to the reduced availability of stroke units and the strain that intensive care units were under [20].

As mortality and irreversible sequelae depend on the timeliness of treatment, and considering the high prevalence of stroke, the reduced or delayed hospitalizations will have huge health, social, and economic consequences.

The rushed reorganization of hospitals imposed by the high transmissibility of the SARS-CoV-2 has resulted in a general difficulty for patients and the public to obtain reliable information, particularly in those regions most affected by the pandemic. As can be seen in the example of the effects on stroke units discussed above, the conflicting information provided by the media has increased alarm and confusion, since even small communication errors can have significant consequences during a pandemic [21]. A more precise assessment of these "side effects" of the pandemic will only become clearer over time. Nevertheless, it appears that clear and transparent information is essential to empowering and supporting the community in general, and particularly during crises [22]. The initial uncertainties about almost all the characteristics of SARS-CoV-2 virus have posed new challenges to the ways of understanding and organizing health communication [23]. After 7 months, the accumulated knowledge shows that it is necessary to change the pace of public communication strategies and campaigns, aiming them not only at adopting safe behaviors key to reducing the spread of the virus but also at these "side effects" such as reduced hospitalisations due to the fears of the general public.

\section{Reflecting on neurological preparedness}

Italian neurologists and allied professionals have soon responded to the consequences of the pandemic, dealing not only with the reorganization of neurological emergency units, chiefly stroke units and networks [24-26], but also providing activities in the newborn COVID units. Telemedicine, including telephone follow-up consultations and remote patient monitoring, has been used to preserve care continuity [27-30]. Ad hoc registries have been established to assess disease-specific risks and to guide the treatment of patients with immune conditions such as multiple sclerosis and myasthenia gravis [31, 32]. These experiences are particularly valuable as the Italian healthcare system is organized at the regional level, with consistent differences across regions.

In view of the variable response capacity showed by the national healthcare systems and the economic crisis that is expected to extend beyond the emergency, there is a need to urgently consider the implementation of resource allocation strategies. This should start from "ordinary" situations to avoid the health care system finding itself again in a crisis during and after the "extraordinary."

Before the pandemic, the health care resources (including those of the public solidaristic systems) were inadequate due to unfair distribution and organization. Previous emergency periods, including Ebola, SARS, and the flu epidemics, had already shown that there were real difficulties in maintaining the usual levels of care for frail patients, due to saturation of facilities available both at the community and hospital levels [33-35].

It is thus imperative to identify the possible strategies to be implemented locally to meet at best the needs of acute and especially chronic neurological patients, during both "ordinary" and emergency periods.

Having critically appraised what happened before and during the first pandemic peak, we would suggest the following five strategies:

1. Care pathways based on the intensity of care would help to overcome the hospital-community dichotomy, and make it possible to treat most of the neurological symptoms and complications, which are currently managed in the emergency unit (e.g., epileptic seizures, agitation with dementia, uncontrolled pain), at the community or outpatient level. This would reduce costly and useless (if not harmful) hospital admissions/re-admissions; increase the appropriateness and reduce the length of stay of these admissions; and increase the use of day/week hospitalizations for elective procedures. This re-organization requires an interdisciplinary network that involves hospital and community levels, as well as training programs for health care professionals, and formal and informal caregivers [36].

2. Advanced health and social care integration would help to ensure continuity of care and help patients and family members feel less isolated. The use of technological equipment, such as telemedicine and video consultation, has a key role to play, provided that equal access to care remains a priority [37]. Thus, the most appropriate approach should be planned by direct involvement of the patient and his/her significant others, to best meet patient needs, habits, and preferences.

3. Enhanced (neuro) palliative care. The oncology model, where palliative care first developed, adapts poorly to the trajectories of many persons with chronic progressive neurological disorders. These persons may require early palliative care together with active neurological care, and this may vary over time, and may stretch over long periods. Thus, it is essential to train neurology health 
professionals in palliative medicine, and palliative care professionals in neurology.

4. ACP and advance directives. It is essential that good care planning be undertaken to ensure that patients can choose which treatments they will receive from the menu of those that are available and most appropriate, even during the pandemic. Proactive planning and advance treatment arrangements should be a standard component of care provided by neurologists and primary care physicians [38]. However, after over 2 years from the passage of the Italian Law 219/2017, the implementation of ACP is very limited [39]. Neurologists and the other health professionals should be trained to having these conversations.

5. Public communication and information campaigns. It is important to keep the public informed about the measures and behaviors to adopt during the pandemic, but it is also important to ensure that they are aware of the safety of health care facilities, encouraging them to contact emergency networks in the event of acute neurological symptoms [40-42].

\section{Conclusions}

The aim of this paper is to show how this extraordinary pandemic, caused by the spread of SARS-CoV-2 virus, has challenged clinical activity and education in neurology. A balance needs to be struck between finding the right pathway to facing and solving the issue of criteria for accessing care and the need to focus on the clinical and legal context of care for chronic neurological patients. This dilemma highlights the importance and urgency of preparedness in designing action strategies in public health, so as to be ready for other possible emergencies caused by pandemics. The role of telemedicine has been highlighted as the technology can make it possible to continue outpatient care at home, and limit exposure to infection. ACP programs can help neurologists make the right ethical decisions, in keeping with the fundamental principles of good care and the wellbeing of their patients, while respecting patients' autonomy. It is essential that the actions and choices made in any emergency situation, such as during the COVID-19 pandemic, are fully transparent and backed by broad consensus, and that this reorganization of health and social services does not imperil frail individuals, including those with neurological disorders, once the pandemic is over.

Acknowledgments We thank Prof. David Oliver, Canterbury (UK) and Filippo Valente for their advice and help with the English.

Authors' contributions SZ, FI, VC, MC, RD, MG, CL, AL, MMa, MMo, $\mathrm{FP}, \mathrm{CP}, \mathrm{MV}, \mathrm{EP}$, and AS contributed to the study conception and design, and to data collection. SZ, FI, VC, RD, FP, CP, EP, and AS drafted the manuscript. SZ, FI, VC, AL, FP, CP, SV, EP, and AS critically revised the manuscript. All authors read and approved the final manuscript.
Data availability Not applicable.

\section{Compliance with ethical standards}

Conflict of interest None declared.

Ethical approval None.

Informed consent None.

Code availability Not applicable.

\section{References}

1. Government of Italy. Decree of the President of the Council of Ministers 11 March 2020. https://www.gazzettaufficiale.it/eli/id/ 2020/03/11/20A01605/sg. Accessed 15 September 2020

2. Italian Ministry of Health. http://www.salute.gov.it/imgs/C_17 notizie_4694_0_file.pdf. Accessed 15 September 2020

3. Bersano A, Pantoni L (2020) On being a neurologist in Italy at the time of the COVID-19 outbreak. Neurology 94(21):905-906. https://doi.org/10.1212/WNL.0000000000009508

4. Rubin MA, Bonnie RJ, Epstein L, Hemphill C, Kirschen M, Lewis A, Suarez JI, Ethics, Law, and Humanities Committee, a joint committee of the American Academy of Neurology, American Neurological Association, and Child Neurology Society; in collaboration with the Neurocritical Care Society Ethics Committee (2020) AAN position statement: the COVID-19 pandemic and the ethical duties of the neurologist. Neurology 95(4):167-172. https:// doi.org/10.1212/WNL.0000000000009744

5. Fuentes B, Alonso de Leciñana M, Calleja-Castaño P, CarneadoRuiz J, Egido-Herrero J, Gil-Núñez A, Masjuán-Vallejo J, Vivancos-Mora J, Rodríguez-Pardo J, Riera-López N, XiménezCarrillo Á, Cruz-Culebras A, Gómez-Escalonilla C, Díez-Tejedor E, en representación de los hospitales del Plan Ictus Madrid (2020) Impact of the COVID-19 pandemic on the organisation of stroke care. Madrid Stroke Care Plan. Neurologia 35(6):363-371

6. Leocani L, Diserens K, Moccia M, Caltagirone C (2020) Disability through COVID-19 pandemic: neurorehabilitation cannot wait. Eur J Neurol 27:e50-e51. https://doi.org/10.1111/ene.14320

7. Brown EG, Chahine LM, Goldman SM, Korell M, Mann E, Kinel DR, Arnedo V, Marek KL, Tanner CM (2020) The effect of the COVID-19 pandemic on people with Parkinson's disease. J Parkinsons Dis 10:1365-1377. https://doi.org/10.3233/JPD202249

8. Cheong JLY, Goh ZHK, Marras C, Tanner CM, Kasten M, Noyce AJ, Movement Disorders Society Epidemiology Study Group (2020) The impact of COVID-19 on access to Parkinson's disease medication. Mov Disord. https://doi.org/10.1002/mds.28293

9. Wirrell EC, Grinspan ZM, Knupp KG, Jiang Y, Hammeed B, Mytinger JR, Patel AD, Nabbout R, Specchio N, Cross JH, Shellhaas RA (2020) Care delivery for children with epilepsy during the COVID-19 pandemic: an international survey of clinicians. J Child Neurol:883073820940189. https://doi.org/10.1177/ 0883073820940189

10. Provinciali L, Carlini G, Tarquini D, Defanti CA, Veronese S, Pucci E (2016) Need for palliative care for neurological diseases. Neurol Sci 37(10):1581-1587. https://doi.org/10.1007/s10072-016-2614-x

11. Bhaskar S, Bradley S, Israeli-Korn S, Menon B, Chattu VK, Thomas P, Chawla J, Kumar R, Prandi P, Ray D, Golla S, Surya N, Yang H, Martinez S, Ozgen MH, Codrington J, González EMJ, Toosi M, Hariya Mohan N, Menon KV, Chahidi A, Mederer 
Hengstl S (2020) Chronic neurology in COVID-19 era: clinical considerations and recommendations from the REPROGRAM Consortium. Front Neurol 11:664. https://doi.org/10.3389/fneur. 2020.00664

12. Hernández Ramos FJ, Palomino García A, Jiménez Hernández MD (2020) Neurology during the pandemic. Is COVID-19 changing the organisation of Neurology Departments? Neurologia 35(4):269271. https://doi.org/10.1016/j.nrl.2020.04.009

13. Naccarato M, Scali I, Olivo S, Ajčević M, Buoite Stella A, Furlanis G, Lugnan C, Caruso P, Peratoner A, Cominotto F, Manganotti P (2020) Has COVID-19 played an unexpected "stroke" on the chain of survival? J Neurol Sci 414(15):1-4

14. Ikenberg B, Hemmer B, Dommasch M, Kanz KG, Wunderlich S, Knier B (2020) Code stroke patient referral by emergency medical services during the public COVID-19 pandemic lockdown. J Stroke Cerebrovasc Dis 29(11):105175. https://doi.org/10.1016/j. jstrokecerebrovasdis.2020.105175

15. Esenwa C, Parides MK, Labovitz DL (2020) The effect of COVID19 on stroke hospitalizations in New York City. J Stroke Cerebrovasc Dis 29(10):105114. https://doi.org/10.1016/j. jstrokecerebrovasdis.2020.105114

16. Markus HS, Brainin M (2020) COVID-19 and stroke-a global world stroke organization perspective. Int J Stroke 15(4):361364. https://doi.org/10.1177/1747493020923472

17. Fridman S, Bullrich MB, Jimenez-Ruiz A, Costantini P, Shah P, Just C, Vela-Duarte D, Linfante I, Sharifi-Razavi A, Karimi N, Bagur R, Debicki DB, Gofton TE, Steven DA, Sposato LA (2020) Stroke risk, phenotypes, and death in COVID-19: systematic review and newly reported cases. Neurology 15 . https://doi.org/10. 1212/WNL.0000000000010851

18. Montaner J, Barragán-Prieto A, Pérez-Sánchez S, EscuderoMartínez I, Moniche F, Sánchez-Miura JA, Ruiz-Bayo L, González A (2020) Break in the stroke chain of survival due to COVID-19. Stroke 51(8):2307-2314. https://doi.org/10.1161/ STROKEAHA.120.030106

19. Baracchini C, Pieroni A, Viaro F, Cianci V, Cattelan AM, Tiberio I, Munari M, Causin F (2020) Acute stroke management pathway during Coronavirus-19 pandemic. Neurol Sci 41(5):1003-1005. https://doi.org/10.1007/s10072-020-04375-9

20. Bersano A, Kraemer M, Touzé E, Weber R, Alamowitch S, Sibon I, Pantoni L (2020) Stroke care during the COVID-19 pandemic: experience from three large European countries. Eur J Neurol 27: 1794-1800. https://doi.org/10.1111/ene. 14375

21. Sonekar HB, Ponnaiah M (2020) Emergence of coronavirus (COVID-19) outbreak: anthropological and social science perspective. Disaster Med Public Health Prep:1-3. https://doi.org/10.1017/ dmp.2020.203

22. Brivio E, Oliveri S, Pravettoni G (2020) Empowering communication in emergency contexts: reflections from the Italian coronavirus outbreak. Mayo Clin Proc 9(5):849-851. https://doi.org/10.1016/j. mayocp.2020.03.021

23. Finset A, Bosworth H, Butow P, Gulbrandsen P, Hulsman RL, Pieterse AH, Street R, Tschoetschel R, van Weert J (2020) Effective health communication - a key factor in fighting the COVID-19 pandemic. Patient Educ Couns 103(5):873-876. https://doi.org/10.1016/j.pec.2020.03.027

24. Zedde M, Pezzella FR, Paciaroni M, Corea F, Reale N, Toni D, Caso V (2020) Stroke care in Italy: an overview of strategies to manage acute stroke in COVID-19 time. Eur Stroke J 5(3):222229. https://doi.org/10.1177/2396987320942622

25. Paolucci M, Biguzzi S, Cordici F, Lotti EM, Morresi S, Romoli M, Strumia S, Terlizzi R, Vidale S, Menarini M, Ruggiero M, Valentino A, Longoni M (2020) Impact of COVID-19 pandemic on acute stroke care: facing an epidemiological paradox with a paradigm shift. Neurol Sci. https://doi.org/10.1007/s10072-020-04914-4
26. Candeloro E, Carimati F, Tabaee Damavandi P, Princiotta Cariddi L, Banfi P, Clemenzi A, Gallazzi M, Mauri M, Rebecchi V, Baruzzi F, Giorgianni A, Tozzi M, Bianchi M, Ageno W, Versino M (2020) An example of a stroke unit reshaping in the context of a regional hub and spoke system in the COVID-19 era. Front Neurol 11:1029. https://doi.org/10.3389/fneur.2020.01029

27. Postiglione E, Pizza F, Ingravallo F, Vignatelli L, Filardi M, Mangiaruga A, Antelmi E, Moresco M, Oriolo C, Pagotto U, Plazzi G (2020) Impact of COVID-19 pandemic lockdown on narcolepsy type 1 management. Brain Behav. https://doi.org/10. 1002/brb3.1955

28. De Marchi F, Sarnelli MF, Serioli M, De Marchi I, Zani E, Bottone N, Ambrosini S, Garone R, Cantello R, Mazzini L, CANPALS Study Group (2020) Telehealth approach for amyotrophic lateral sclerosis patients: the experience during COVID-19 pandemic. Acta Neurol Scand. https://doi.org/10.1111/ane.1337

29. Motolese F, Magliozzi A, Puttini F, Rossi M, Capone F, Karlinski K, Stark-Inbar A, Yekutieli Z, di Lazzaro V, Marano M (2020) Parkinson's disease remote patient monitoring during the COVID-19 lockdown. Front Neurol 11:567413. https://doi.org/10. 3389/fneur.2020.567413

30. Delussi M, Gentile E, Coppola G, Prudenzano AMP, Rainero I, Sances G, Abagnale C, Caponnetto V, de Cesaris F, Frattale I, Guaschino E, Marcinnò A, Ornello R, Pistoia F, Putortì A, Roca ME, Roveta F, Lupi C, Trojano M, Pierelli F, Geppetti P, Sacco S, de Tommaso M (2020) Investigating the effects of COVID-19 quarantine in migraine: an observational cross-sectional study from the Italian National Headache Registry (RICe). Front Neurol 11: 597881. https://doi.org/10.3389/fneur.2020.597881

31. Sormani MP (2020) An Italian programme for COVID-19 infection in multiple sclerosis. Lancet Neurol 2020

32. Muppidi S, Guptill JT, Jacob S, Li Y, Farrugia ME, Guidon AC, Tavee JO, Kaminski H, Howard JF Jr, Cutter G, Wiendl H, Maas MB, Illa I, Mantegazza R, Murai H, Utsugisawa K, Nowak RJ, Guidon AC, Tyagi A, Sousa AP, Amato AA, Pinto A, Roy B, Carmichael C, Dodig D, Burke G, Cutter GR, Kaminski HJ, Wiendl H, Murai H, Lee I, Illa I, Guptill J, Howard JF Jr, Caress J, Pritchard J, Tavee JO, Vissing J, Best K, Utsugisawa K, Ramezani M, Maas M, Farrugia ME, Hehir MK, Kaku M, Esquivel NJ, Gallagher P, Maddison P, Ambrose PA, Mantegazza RE, Nowak RJ, Do Campo RV, Jacob S, Saba S, Nafissi S, Itoyama S, Muppidi S, Viegas SV, Marshall V, Li YL (2020) COVID-19associated risks and effects in myasthenia gravis (CARE-MG). Lancet Neurol 19(12):970-971. https://doi.org/10.1016/S14744422(20)30413-0

33. Christian MD, Joynt GM, Hick JL, Colvin J, Danis M, Sprung CL, European Society of Intensive Care Medicine's Task Force for intensive care unit triage during an influenza epidemic or mass disaster (2020) Critical care triage. Recommendations and standard operating procedures for intensive care unit and hospital preparations for an influenza epidemic or mass disaster. Intensive Care Med 36(Suppl 1):S55-S64. https://doi.org/10.1007/s00134-010-17650

34. Strosberg MA (2006) Allocating scarce resources in a pandemic: ethical and public policy dimensions. Ethics Journal of the American Medical Association 8(4):241-244

35. Veatch RM (2005) Disaster preparedness and triage: justice and the common good. Mt Sinai J Med 72:236-241 Available at: http:// www.mssm.edu/msjournal/72/72_4 pages_236_241.pdf

36. van der Meulen M, Kleineberg NN, Schreier DR, García-Azorin D, di Lorenzo F (2020) COVID-19 and neurological training in Europe: from early challenges to future perspectives. Neurol Sci 41:3377-3379

37. Chaet D, Clearfield R, Sabin JE, Skimming K (2017) Council on Ethical and Judicial Affairs American Medical Association. Ethical practice in telehealth and telemedicine. J Gen Intern Med 32(10): $1136-1140$ 
38. Hopkins SA, Lovick R, Polak L, Bowers B, Morgan T, Kelly MP, Barclay S (2020) Reassessing advance care planning in the light of covid-19. BMJ 369:m1927. https://doi.org/10.1136/bmj.m1927

39. De Panfilis L, Giorgi Rossi P, Mazzini E, Pistolesi L, Ghirotto L, Noto A, Cuocolo S, Costantini M (2020) Knowledge, opinion and attitude about the Italian law on advance directives: a populationbased survey. J Pain Symptom Manag S0885-3924(20):3056130563. https://doi.org/10.1016/j.jpainsymman.2020.06.020

40. Oseran AS, Nash D, Kim C, Moisuk S, Lai PY, Pyhtila J, Sequist TD, Wasfy JH (2020) Changes in hospital admissions for urgent conditions during COVID-19 pandemic. Am J Manag Care 26(8): 327-328. https://doi.org/10.37765/ajmc.2020.43837

41. Zhao J, Li H, Kung D, Fisher M, Shen Y, Liu R (2020) Impact of the COVID-19 epidemic on stroke care and potential solutions. Stroke 51(7):1996-2001
42. Jasne AS, Chojecka P, Maran I, Mageid R, Eldokmak M, Zhang Q, Nystrom K, Vlieks K, Askenase M, Petersen N, Falcone GJ, Wira CR III, Lleva P, Zeevi N, Narula R, Amin H, Navaratnam D, Loomis C, Hwang DY, Schindler J, Hebert R, Matouk C, Krumholz HM, Spudich S, Sheth KN, Sansing LH, Sharma R (2020) Stroke code presentations, interventions, and outcomes before and during the COVID-19 pandemic. Stroke 51(9):2664-2673. https://doi.org/10.1161/STR.0000000000000347

Publisher's note Springer Nature remains neutral with regard to jurisdictional claims in published maps and institutional affiliations. 